\title{
Herbivory and plant growth rate determine the success of El Niño Southern Oscillation-driven tree establishment in semiarid South America
}

\author{
MILENA HOLMGREN*, BERNAT C. LÓPEZ†, JULIO R. GUTIÉRREZ \\ and FRANCISCO A. SQUEO \\ ${ }^{*}$ Resource Ecology Group, Wageningen University, Bornsesteeg 69, Building 119, 6708 PD Wageningen, The Netherlands, \\ $\dagger C R E A F$ (Center for Ecological Research and Forestry Applications) and Unit of Ecology, Department of Animal and \\ Plant Biology and Ecology, Autonomous University of Barcelona (UAB), E-08193 Bellaterra, Catalonia, Spain, \\ $\ddagger$ Departamento de Biología, Facultad de Ciencias, Universidad de La Serena, Centro de Estudios Avanzados en Zonas Aridas \\ (CEAZA) and Instituto de Ecología y Biodiversidad (IEB), Casilla 599, La Serena, Chile
}

\begin{abstract}
While climatic extremes are predicted to increase with global warming, we know little about the effect of climatic variability on biome distribution. Here, we show that rainy El Niño Southern Oscillation (ENSO) events can enhance tree recruitment in the arid and semiarid ecosystems of north-central Chile and northwest Peru. Tree-ring studies in natural populations revealed that rainy El Niño episodes have triggered forest regeneration in Peru. Field experiments indicate that tree seedling recruitment in Chile is much less successful than in Peru due mostly to larger mortality caused by herbivores. The dramatic impact of herbivores in Chile was derived from the combined result of slower plant growth and the presence of exotic herbivores (European rabbits and hares). The interplay of herbivory and climatic effects we demonstrated implies that rainy ENSO events may represent 'windows of opportunity' for forest recovery if herbivore pressure is minimized at the right moment.
\end{abstract}

Keywords: alternative stable state, climate variability, desertification, herbivore, Prosopis, rainfall, resource pulse, restoration, seedling establishment, vegetation shift

Received 28 March 2006 and accepted 26 June 2006

\section{Introduction}

Arid and semiarid ecosystems occupy $40 \%$ of the Earth's land surface (Millennium Ecosystem Assessment, 2005) and are among the systems predicted to be most sensitive to future changes in climate (IPCC, 2001). As climatic extremes are expected to become more frequent, understanding how these ecosystems respond to present climatic fluctuations can improve our predictions on how they may change in the future. The El Niño Southern Oscillation (ENSO) cycle is the most prominent source of interannual climatic variation on our planet and affects large area of drylands worldwide (Allan et al., 1996). El Niño-like conditions have become more frequent in the last decades (Trenberth \& Hoar, 1997; Tudhope et al., 2001), and although there are

Correspondence: Milena Holmgren, tel. +31 317 484320,

fax +31 317 484845, e-mail: Milena.Holmgren@wur.nl

(C) 2006 The Authors

Journal compilation (C) 2006 Blackwell Publishing Ltd considerable uncertainties in the prediction of such future events (Collins, 2000; Cobb et al., 2003), ENSO events could increase in magnitude and frequency as result of global climate warming (Timmermann et al., 1999).

During an El Niño phase, there is a shift in the rainfall convective zone towards the eastern Pacific produced by interconnected changes in atmospheric pressure, the strength of the trade winds, and ocean circulation. As a result, drought conditions affect large portions of Australia, Indonesia and the Philippines, while torrential rains can occur in the island states of the central Pacific and along the west coast of South America. This shift in the rainfall convective zone also leads to changes in atmospheric circulation (known as teleconnections) that propagate the influence of $\mathrm{El}$ Niño around the planet. As a consequence, during an El Niño episode, rainfall dramatically increases in certain areas of the world, while severe droughts occur in other regions. The El 
Niño phase lasts approximately 1 year before the climatic conditions often reverse in a La Niña phase. The oscillation between El Niño and La Niña is irregular, but typically occurs once every 3-6 years (Allan et al., 1996; McPhaden, 2004).

As water availability is a limiting factor in arid and semiarid ecosystems, rainy ENSO years trigger an extraordinary response in plant productivity that cascades across trophic levels (Holmgren et al., 2001, 2006). Particularly important are the effects of these large rainfall pulses on the recruitment of trees and shrubs because woody cover expansion can have significant impacts on water and nutrient cycles, diversity of plants and animals and land use activities. Observations from Australia (Austin \& Williams, 1988), the southeastern USA (Brown et al., 1997), and northwest Peru (Vilela, 2002) suggest that extreme rainy ENSO events may trigger long lasting shifts in semiarid vegetation by facilitating the establishment of trees and shrubs. Effects of these rainy pulses, however, appear to differ widely between regions. For instance, in contrast to the Peruvian situation, long-term observations in north-central Chile show hardly any change in shrub cover after rainy ENSO events (Gutiérrez et al., 1997). It is likely that differences in woody cover regeneration during ENSO events are partly modulated by herbivore pressure (Holmgren \& Scheffer, 2001). Indeed synchronized reduction in herbivory during these rainy pulses has been key to explain woody regeneration in Australia (Austin \& Williams, 1988) and the Sonoran Desert (Bowers, 1997).

In this paper, we show correlations between tree recruitment and rainy ENSO events in north-central Chile and northwest Peru, and present evidence for the idea that the differences in response between these regions may be explained by variations in herbivory pressure and plant growth rate. Our analysis is based on a combination of tree-ring studies and controlled field experiments.

\section{Materials and methods}

\section{Study species}

We studied one native tree species from Peru (Prosopis pallida H.B.K.) and one from Chile (Prosopis chilensis Mol Stuntz) both belonging to a genus that is widely distributed in South America (Pasiecznik, 2001). P. pallida is a dominant species in the dry forests of north Peru and highly valuable for the local rural economies. P. chilensis used to have a wide distribution from the hyperarid to semiarid zones in Chile (Arce \& Balboa, 1989) before indiscriminated logging and grazing reduced it to a species in vulnerable state with only scatter adult individuals (Squeo et al., 2001). Both tree species are considered priority targets for local reforestation programs (Arce \& Balboa, 1989; Vilela, 2002).

\section{Study sites}

Fray Jorge (north-central Chile). The experimental site was located next to the Fray Jorge Forest National Park, $85 \mathrm{~km}$ south of La Serena and $25 \mathrm{~km}$ from the highway $\left(30^{\circ} 41^{\prime} \mathrm{S}, 71^{\circ} 37^{\prime} \mathrm{W}\right)$ on a south-east faced gentle slope $\left(10^{\circ} ; 200 \mathrm{~m}\right.$ a.s.l.), within a private farm (Fundo El Salitre). This old-field site is currently being used for livestock grazing.

The climate is semiarid Mediterranean with the precipitation concentrated in the winter months (MaySeptember); summer months are warm and dry. Mean annual precipitation is $145.4 \pm 31.3 \mathrm{~mm}$ (1SE; 19892002, Weather Station at Fray Jorge). Longer meteorological records from La Serena $(60 \mathrm{~km}$ north) report an average of $114.4 \mathrm{~mm}$ (1878-1998, Soto \& Ulloa, 1997). High-rainfall events are associated with the ENSO phenomenon (Aceituno \& Montecinos, 1992). In rainy El Niño years, annual precipitation averages $174 \mathrm{~mm}$ (years 1875-2000), with occasional strong events over $200 \mathrm{~mm}$ (e.g. in 1997, 233.4 mm, 1905, $487 \mathrm{~mm}$ which is the strongest recorded event). In contrast to the top ridges of the coastal mountain range, fog is not an important source of water availability in lowlands such as our study site (Squeo et al., 2006). Mean annual temperature is $13.6^{\circ} \mathrm{C}(1998$ 2003), January is the warmest month (ca. $17^{\circ} \mathrm{C}$ ) and July is the coldest one (ca. $10^{\circ} \mathrm{C}$; López-Cortes \& López, 2004). Annual potential evapotranspiration reaches $1000 \mathrm{~mm}$.

Piura (northwest Peru). The experimental site was located within the University of Piura campus $\left(5^{\circ} 10^{\prime} \mathrm{S}\right.$, $80^{\circ} 37^{\prime} \mathrm{W} ; 30 \mathrm{~m}$ a.s.1.). Rainfall is concentrated in the summer months (December-May) and strongly influenced by ENSO events (Ortlieb, 2000). Although mean annual precipitation is $50 \mathrm{~mm}$ (1961-1983; Bernex de Falen \& Reves, 1988), it is highly variable (e.g. ranging from $2.8 \mathrm{~mm}$ in 1996 to $1639 \mathrm{~mm}$ in 1998). Mean annual temperature is $24^{\circ} \mathrm{C}$, being warmest in February $\left(27.9^{\circ} \mathrm{C}\right)$ and coolest in August $\left(21.1^{\circ} \mathrm{C}\right)$. Annual potential evapotranspiration reaches $1825 \mathrm{~mm}$.

\section{Dendrochronological studies}

In January 2002, we took a total of 228 P. pallida wood samples from seven different locations around Piura, north Peru. In January 2003, we took 190 samples from $P$. chilensis trees from seven locations of the Coquimbo Region, north-central Chile. In both countries, we 
sampled only natural populations that had clearly not been under irrigation. In Peru, tree samples consisted of tree disks from recently cut trees, which are abundantly found in the region. In Chile, we took one tree core per tree at the base of the trunk using a special borer for hard wood (HD-borer $300 \mathrm{~mm}$ Patience \& Nicholson, Aust. Pty Ltd, Kaipoi, New Zealand) connected to a gas powered drill (Tanaka TED262R, Tanaka Kogyo Co. Ltd, Narashino-shi, Chiba, Japan).

Samples from Peru and Chile were first rough polished with a belt sander, and then with a sheet sander with sand paper of up to 1000 grit. Samples were observed under a binocular microscope and growth rings were marked with a very finely sharpened pencil. Samples were then scanned at a resolution of $0.015875 \mathrm{~mm}$ using an Epson Expression 1640 XL scan ${ }^{(0)}$ (Seiko Epson Corp., Nagano, Japan). We used WinDENDRO $^{\odot}$ (Regent Instruments Inc., Canada) software to detect rings, but due to the characteristics of growth rings, the software was unable to automatically detect any ring. However, the agility and the ease-to-use of WinDENDRO $^{\odot}$ was of valuable help, so rings were manually marked, using both pencil marks - which were already scanned - and visual criteria through the screen. Ring-width data were cross-dated with COFECHA (Grissino-Mayer, 2001), and only the best correlated series were kept for building a master series for Peru $(n=96)$ and Chile $(n=14)$. To build this master series, the individual ring-width measurement series are standardized by removing the long-term growth trends largely attributed to increasing age and tree size (ARSTAN software). Detrending was done in two steps; first through a negative exponential curve, and second with a cubic smoothing spline (Fritts, 1976; Cook, 1985). Three chronologies result from this process: a standard chronology, a residual chronology (containing only the high-frequency variations) and the ARSTAN chronology (composed of the residual chronology with the pooled autoregression reincorporated). This last series containing the growth index is the one further used.

The two master chronologies (Peru and Chile) were matched against precipitation and temperature data. We used meteorological data from the Universidad de Piura for the Peruvian samples, and from La Serena Airport and the Vicuña weather stations for the Chilean one.

Tree recruitment years were directly obtained for those samples presenting the pith (tree centre), namely all disks from Peru and some P. chilensis tree cores. Using these Chilean samples, we related the distance to the pith with the number of years (no. of years = $-1.6057+0.0608 \times$ pith distance, $R^{2}=0.993, n=13$ ). This regression was used to estimate the establishment date for the rest of the samples. In order to estimate the distance to the pith in the cores that did not reach it, we used standard techniques consisting of matching the tree ring boundary closer to the pith against a template of circles at increasing radii.

For each species, we compared tree growth $\left(\mathrm{mm} \mathrm{yr}^{-1}\right)$ and recruitment (\% of trees) in El Niño vs. non-El Niño years using a $t$-test. The chronology of $P$. chilensis was much longer than the one from P. pallida (1877-2001 vs. 1965-2001, respectively). As older trees are increasingly lost by natural mortality and this unknown factor may distort interpretation of the recruitment patterns, we repeated the same analysis using only the last 20 years data from the Peruvian and Chilean chronologies. We also explored the relationships between tree growth index and recruitment with annual rainfall and the southern oscillation index (SOI) at different time lags through a stepwise linear regression [i.e. tree growth index $\left.=f\left(\mathrm{SOI}_{t}+\mathrm{SOI}_{t-1}+\mathrm{SOI}_{t-2}\right)\right]$.

\section{Field experiments}

\section{Experiment 1: role of herbivory}

This experiment aimed to test the role of herbivores on tree establishment during simulated rainy ENSO conditions. We performed our field experiments with P. chilensis in north-central Chile and P. pallida in north Peru. The herbivory treatments included plants exposed and not exposed to the local herbivores. In each region, we installed five $6 \times 6 \mathrm{~m}^{2}$ plots for each herbivore treatment. In Chile, main herbivores were European rabbits (Oryctolagus cuniculus) and hares (Lepus europaeus) and ocassionally small native rodents (Phyllotis darwini, Akodon olivaceus, Octodon degus). In north Peru, main herbivores were native lizards (Dicrodon gutulatum and Microlophus peruvianus). All large herbivores, mainly domestic livestock, were excluded using a $800 \mathrm{~m}$-perimeter fence around the whole experimental setting. To exclude small herbivores, we used $2 \mathrm{~m}$ high galvanized fences $(0.5 \mathrm{~cm}$ mesh), buried $30 \mathrm{~cm}$ into the ground and with a $25 \mathrm{~cm}$ strip flashing at the upper part of the fence to exclude all small mammals. Before the start of the experiment, we live-trapped small mammals and lizards for 1 day using four traps per plot (160 traps in total) in order to control that no individuals were present in the herbivore-excluded experimental plots.

In north central Chile, the experiment was installed at the end of May 2002. After unsuccessful sowing, 25 P. chilensis plants were planted in each plot following a $5 \times 5$ configuration, with $1 \mathrm{~m}$ distance between plants. We used 9-month-old plants, between 45 and $50 \mathrm{~cm}$ tall, obtained from a greenhouse of CONAF (Chilean Forest Service). Plants in the herbivore-exposed treatments 
were temporarily protected with fences between planting and the beginning of the experimental treatments. In north Peru, the experiment was installed in December 2002. We sowed two seeds of $P$. pallida per future seedling point. Before sowing, seeds were water soaked at $35^{\circ} \mathrm{C}$ for $24 \mathrm{~h}$. After germination, we removed one seedling per sowing point to keep the same design used in Chile.

To simulate ENSO conditions, we watered all plants in addittion to natural rainfall, adding $150 \mathrm{~mm}$ in Chile and $200 \mathrm{~mm}$ in Peru. The experimental irrigation was carried out during the rainy season in each locality following the natural distribution pattern of rainfall. We mimic natural rainfall by sprinkling water through nine $1 \mathrm{~m}$ height microjets per plot that were distributed at $2 \mathrm{~m}$ intervals. Considering the natural rainfall during the growing season and the water added, water availability in Chile reached $487 \mathrm{~mm}$ ( $337 \mathrm{~mm}$ natural rainfall), and $227.4 \mathrm{~mm}$ in north Peru (27.4 natural rainfall). The much higher values reached in Chile were produced by a coincident moderate ENSO event in 2002 (McPhaden, 2004). Plant survival percent at 6 months was compared between the two herbivory treatments at each site.

\section{Experiment 2: role of water}

This experiment was designed to study tree seedling establishment under a simulated range of ENSO intensities in the absence of herbivores. In each experimental site, we applied six water treatments in addition to natural rainfall $(0,50,100,200,400,600 \mathrm{~mm})$. Treatments were replicated in 16 blocks. Drip irrigation was applied during the rainy season in each site using the natural distribution pattern of rainfall. The experimental setting was protected against large and small mammal herbivores using the method previously described for the herbivore control experiment. We removed the aboveground biomass of shrubs growing at the experimental set to avoid either uncontrolled shading and water effects by potential hydraulic lift (Squeo et al., 1999).

In early September 2002, we planted 2-week old $P$. chilensis seedlings in Fray Jorge, and in December of that year we installed the experiment with $P$. pallida seedlings in Piura. Seedlings were $2 \mathrm{~cm}$ high and had emerged cotyledons. We monitored seedling survival and growth twice a month for 6 months. Plant survival percent was transformed (arcsine-square root) to correct for data distribution and water treatment effects were compared through a one-way ANOVA. Differences between treatment means were assessed by a posteriori Tukey test.
Experiment 3: role of plant growth rate

This field experiment compared the growth rate response of both species ( $P$. chilensis and P. pallida) when grown under the same environmental conditions at both locations (Fray Jorge and Piura). We planted 25 one-week-old seedlings of each species in 10 replicated plots at each experimental site. The experiment was carried out between March and September 2003 in Piura, and between September 2003 and March 2004 in Fray Jorge. In each case, we simulated two rainfall events of $75 \mathrm{~mm}$ before plantation and 10 days afterwards, using the previously described drip irrigation method. All plants were protected against herbivores. Plant growth was monitored twice a month for 6 months. We used a factorial ANOVA to compare height growth between both species growing at the two experimental sites. Plots were nested within sites, and the proper error terms were used to test treatment effects.

\section{Results}

\section{Natural tree recruitment and growth: field patterns}

The dendrochronological series of northwest Peru indicate that twice as many P. pallida trees were recruited during ENSO years compared with no-ENSO years, particularly for the last 20 years (Table 1). Around $33 \%$ of the trees were established during years with very high precipitation corresponding to strong or very strong ENSO events (Fig. 1, top panel).

Table 1 Rainfall $(\mathrm{mm} \pm \mathrm{SD})$, mean tree growth $(\mathrm{mm} \pm \mathrm{SD})$ and mean tree recruitment $(\% \pm \mathrm{SD})$ during ENSO and noENSO years for Prosopis pallida (Peru, 1965-2001) and Prosopis chilensis (Chile, 1877-2001)

\begin{tabular}{lccl}
\hline & $\begin{array}{l}\text { ENSO } \\
\text { years }\end{array}$ & $\begin{array}{l}\text { No-ENSO } \\
\text { years }\end{array}$ & $\begin{array}{l}P \\
\text { value }\end{array}$ \\
\hline Peru & & & \\
$\quad$ Rainfall & $690.7 \pm 952.6$ & $39.9 \pm 49.9$ & 0.001 \\
Growth & $5.9 \pm 3.6$ & $3.2 \pm 1.7$ & 0.005 \\
Recruitment & $4.5 \pm 4.2$ & $2.4 \pm 2.4$ & 0.095 \\
Growth (1980-2001) & $7.0 \pm 2.9$ & $2.5 \pm 1.0$ & 0.001 \\
Recruitment (1980-2001) & $7.1 \pm 3.5$ & $3.5 \pm 2.5$ & 0.028 \\
Chile & & & \\
Rainfall & $174.1 \pm 120.2$ & $111.2 \pm 85.6$ & 0.003 \\
Growth & $1.9 \pm 1.1$ & $1.8 \pm 0.9$ & 0.845 \\
Recruitment & $0.43 \pm 1.1$ & $0.9 \pm 1.6$ & 0.161 \\
Growth (1980-2001) & $2.5 \pm 0.4$ & $2.1 \pm 0.5$ & 0.076 \\
Recruitment (1980-2001) & $0.30 \pm 0.30$ & $0.72 \pm 0.32$ & 0.556 \\
\hline
\end{tabular}

For the whole series at each site, ENSO years are seven in Peru and 25 in Chile); and no-ENSO years are 27 in Peru and 100 in Chile.

ENSO, El Niño Southern Oscillation. 



Fig. 1 Annual rainfall, Southern Oscillation Index (SOI) and percentage of recruited Prosopis pallida trees in Peru (top panel) and Prosopis chilensis trees in Chile (bottom panel).

Tree-ring growth also doubled during ENSO years. In fact, during the last 2 decades the difference between growth in ENSO vs. no-ENSO years has increased to become 2.8 times greater during the rainy ENSO events (Table 1). This is also evident in the high correlation between tree-ring growth and annual precipitation (Pearson's Correlation 0.66, $P<0.01$ ), and the SOI (linear regression, all years, $P=0.05$; last 20 years, $P=0.03$ ). Growth was especially strong in 1983 and 1998, the years with the strongest ENSO events of the last century (Fig. 1, top panel).

In contrast, the tree-ring chronologies for $P$. chilensis showed no significant correlation between the percentage of trees established during certain year and the annual rainfall (Fig. 1, bottom panel). Also, we found no differences in tree growth between ENSO and no ENSO years when using the whole series, although there was a trend towards higher tree growth during ENSO events in the last 2 decades (Table 1). We did find a significant correlation between growth and the SOI for both the whole series $(P<0.0001)$ and the last 20 years $(P<0.0001$; Fig. 1, bottom panel). We also found a weak but significant correlation between tree-ring growth index and annual precipitation (Pearson's Correlation $0.365, P<0.05$, since 1957).

Growth rate of the two species were significantly different ( $t$-test, $P<0.001$ ). Diameter growth rate of P. pallida was $7.1 \pm 4.4 \mathrm{~mm} \mathrm{yr}^{-1}$ (1965-2001), while for P. chilensis was only $4.5 \pm 3.7 \mathrm{~mm} \mathrm{yr}^{-1}$ (1915-2002). Differences were also significant when using data only from the last two decades ( $t$-test, $P=0.03$ ).

\section{Experimental results}

Herbivory by native lizards in north Peru reduced $P$. pallida survival to only $31 \%$ in unprotected plots (Fig. 2). 


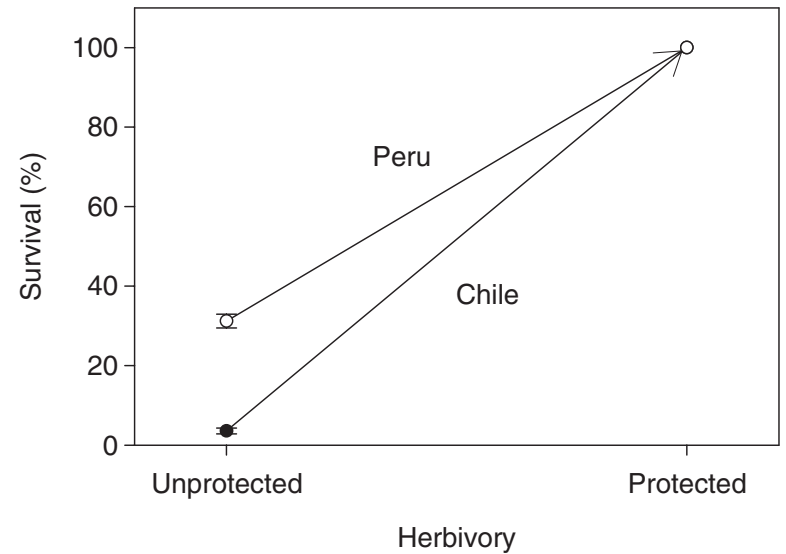

Fig. 2 Survival of Prosopis pallida (Peru) and Prosopis chilensis (Chile) growing in protected and unprotected plots under simulated rainy El Niño Southern Oscillation conditions after 6 months of plantation. Data are mean \pm SE ( $n=5$ plots with 25 seedlings).

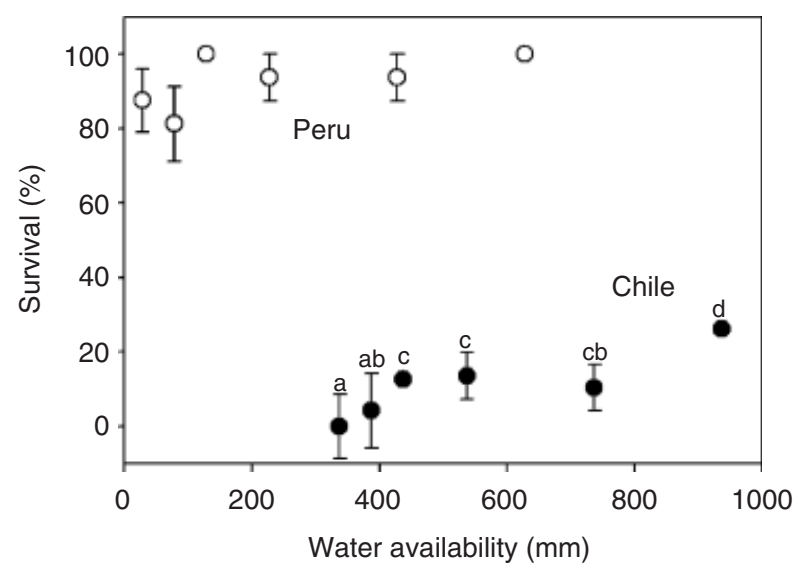

Fig. 3 Survival of protected Prosopis chilensis (Chile) and Prosopis pallida (Piura) growing along a gradient of water availability after 6 months. We used six water treatments in addition to natural rainfall $(0,50,100,200,400,600 \mathrm{~mm})$. Natural precipitation was $337 \mathrm{~mm}$ (Chile) and $27.4 \mathrm{~mm}$ (Peru). There were no statistical differences between treatment means in Peru. Same letters indicate no statistical differences between means in Chile. Data are mean \pm SE $(n=16)$.

In north-central Chile, herbivory played an overwhelming role in the establishment of new trees, reducing survival of $P$. chilensis plants to just $3.6 \%$ in unprotected plots (Fig. 2). After almost 2 years, survival was reduced even further to only $0.3 \%$ (Gutiérrez et al., 2007).

In the absence of herbivores, survival of $P$. pallida seedlings in Piura was very high under all water treatments (Fig. $3, F_{5,90}=1.27 ; P=0.285$ ). With only $27 \mathrm{~mm}$ natural rainfall (no extra irrigation), survival was more than $85 \%$ after 6 months and remained this high after

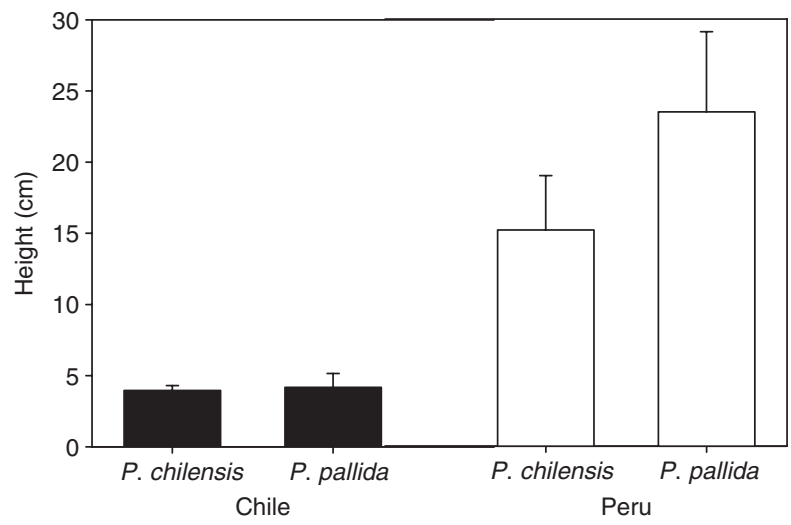

Fig. 4 Height of Prosopis chilensis and Prosopis pallida growing in Piura (Peru) and Fray Jorge (Chile) after 6 months. Data shows mean \pm SE ( $n=10$ plots, with 25 seedlings each).

1 year in treatments that reached more than $90 \mathrm{~mm}$ of water availability during this whole period (Squeo et al., 2007). In contrast, survival of $P$. chilensis seedlings was around six times lower and responded clearly to increasing water availability (Fig. $3 ; F_{5,90}=6.67, P<0.001$ ). Seedling survival was near $10 \%$ with $450 \mathrm{~mm}$ or more after 6 months. After 1 year, no seedlings survived below $500 \mathrm{~mm}$ water availability and survival reached only $8 \%$ at higher water levels (Squeo et al., 2007).

Both species grew much faster in northwest Peru than they did in north-central Chile (Fig. 4; $F_{1,26}=11.29$; $P=0.0024)$. After 6 months, $P$. chilensis seedlings were 3.83 times taller in Peru than they were in Chile, and the $P$. pallida ones were 5.6 taller in Peru. There was no difference between species at each site $\left(F_{1,26}=1.06\right.$; $P=0.3133)$, and no interaction effects between species and site $\left(F_{1,26}=1.16 ; P=0.2916\right)$.

\section{Discussion}

ENSO events have profound effects on the dynamics of arid and semiarid ecosystems worldwide (Holmgren et al., 2001, 2006). The rainy phases of this climatic oscillation can increase tree establishment and produce long-lasting ecosystem effects but the evidence varies across semiarid ecosystems (Holmgren \& Scheffer, 2001). We hypothesized that these different outcomes could be explained by differences in herbivory and plant growth rate during the water pulses.

Our experiments show that in Chile, herbivory effects are a bottleneck for seedling survival. Even under high water availability conditions, no plants survived when unprotected. Main herbivores in Chile are European rabbits (Oryctolagus cunniculus) and hares (L. europaeus). These two species were introduced about a century ago and have proven to be extremely damaging for native 
shrubs and trees (Fuentes et al. 1983, 1984; Jaksic \& Fuentes, 1991). However, even when protected from herbivores, only around $8 \%$ of the 2-week-old $P$. chilensis seedlings survived at experimental water conditions equivalent to very strong Niño events in Chile (Fig. 3). Mortality dropped at older stages. Under the same experimental conditions, 9-month-old plants reached $100 \%$ survival (Fig. 2). Likely older plants can better cope with water stress and make better use of a water pulse than very young seedlings because of a better-developed root system. As our simulated rainy ENSO conditions in Chile were equivalent to very strong events, this suggests that windows of opportunity for tree establishment in Chile are very rare, and that prevalent environmental conditions are extremely hard for the recruitment of new trees.

The situation in Peru contrasts strongly to the Chilean conditions. The tree-ring data of northwest Peru indicate that twice as many $P$. pallida trees were recruited during ENSO years compared with no-ENSO years over the last 20 years. Also, tree mean annual growth rate is correlated with annual rainfall here, whereas in northern Chile we see no such relationship (López et al., 2005, 2006). ENSO events are about 10 times stronger in northwest Peru than they are in north-central Chile. We could speculate that this difference in the rainy pulse intensity is the clue to understand the success of tree recruitment in Peru. However, our field experiments show that, when protected from herbivores, tree seedlings in northwest Peru can successfully establish with only $27 \mathrm{~mm}$ of precipitation, and that increased water availability does not significantly improve early survival. Intrinsic species differences do not seem to be an explanation for the successful tree establishment in Peru either. In fact, when both Prosopis species were planted together, they responded in comparable ways growing much faster in Peru than in Chile (Fig. 4).

All this indicates that overall environmental conditions for tree growth and establishment are much better in Peru. Even in the presence of herbivores, survival of P. pallida seedlings reached $31 \%$, and when herbivores were absent, survival was close to $85 \%$ with only $27 \mathrm{~mm}$ of water. This suggests that environmental factors other than annual rainfall might be affecting plant growth and survival. Rainfall seasonality and temperature are likely crucial factors. The annual mean temperature is $24^{\circ} \mathrm{C}$ in Peru with rainfall concentrated in summer months. In north-central Chile, with a mean annual temperature of only $13.6^{\circ} \mathrm{C}$ and winter rainfall, plant growth is more than four times slower. It is possible that differences in soil texture between our study regions could reinforce differences in plant growth rate. Northwest Peru is characterized by more sandy soils with low resistance for root growth. Indeed root depth growth after 1 year was over $100 \mathrm{~cm}$ in Piura compared with nearly half of that in north-central Chile (Squeo et al., 2007). Desert sandy soils have higher infiltration rates and lower evaporation rates compared with heavier soils which could further favour root development (Noy-Meir, 1973).

The higher growth rates in Peru may allow a larger fraction of the seedlings to quickly reach a size at which they are less vulnerable to herbivory and drought. Fast root growth of Prosopis in north Peru may allow them to reach deeper water sources and overcome drought after the rainy ENSO events. Fast stem growth could also facilitate reaching a safer size against small herbivores such as lizards. Indeed, other studies have shown that plant growth rate and biomass allocation affect the capacity of tree seedlings to establish in the face of herbivory (Strauss \& Agrawal, 1999) and drought (Lynch, 1995), and that as a result, the mortality rate among taller and older individuals tends to decrease (Toft, 1995; Watson et al., 1997).

In addition to plant growth conditions, herbivore pressure may well be more benign in Peru than in Chile. Rabbits and hares are not only larger than lizards but they also have a browsing behavior that implies that plants are vulnerable to stem damage and potential death for longer periods. If we consider the slow plant growth rate in Chile, then is very likely that an escape from herbivory is extremely difficult.

Previous regional comparisons have established that water availability is a primary determinant of the potential woody cover that can be reached by semiarid systems (Sankaran et al., 2005), but that actual woody cover depends also on disturbance regimes (herbivory and fire) and soil types (Scholes \& Archer, 1997; Sankaran et al., 2004). Our work illustrates this same principle, highlighting the importance of understanding the interplay of interannual variation in precipitation with herbivory for explaining successful tree recruitment. The combination of extreme rainy events with reduced herbivory seems to be key to understand woody cover expansion in many semiarid ecosystems. Some of the most striking examples have been described for semiarid Australia where the combination of rainy ENSO events with reduced grazing by either livestock or rabbits has repeatedly triggered the natural regeneration of Eucalyptus and Callitris woodlands (Austin \& Williams, 1988). Similarly, the shrub expansion at the expense of dry grasslands in the Chihuahuan Desert over the past decades has been correlated with wetter winters associated to ENSO events (Brown et al., 1997). Analyzing patterns on a longer time scale, Fredrickson et al. (2006) argued that ancient periods of woody cover expansion in the Chihuahuan Desert may be explained by drops in tree consumption (by Pleistocene fauna and 
later indigenous people) combined with conditions that facilitated tree recruitment such as enhanced seed dispersion and favorable climatic conditions that improved tree establishment and survival.

In summary, our results indicate that ENSO rainy events might open windows of opportunity for tree recruitment in semiarid ecosystems depending on herbivore pressure and plant growth rate. These insights have two important implications. First, restoration programs of degraded semiarid landscapes could be coupled to the climatic swings depending on local conditions. Our results indicate that in regions such as northwest Peru, natural regeneration of dry forests is very likely. In regions such as north-central Chile, predicted rainy ENSO events could also have a positive effect on tree establishment but only if herbivores were actively controlled. Second, our results have implications for predictions of climate change effects. The last two decades have been marked by unusually strong and frequent El Niño events that suggest a potential humaninduced greenhouse warming effect on the behavior of the ENSO phenomenon (Trenberth \& Hoar, 1997; Tudhope et al., 2001). If the frequency of El Niño events increases during the coming decades (Timmermann et al., 1999), this will most probably result in an expansion of dry forests in certain semi-arid regions.

\section{Acknowledgements}

We thank the careful review of the subject editor and two anonymous reviewers. We also thank Cajo ter Braak for advise on the statistical analyses and Marten Scheffer for his valuable insights. Carlos Gracia, Rodolfo Rodríguez and Santi Sabaté assisted on tree-ring data acquisition. Mario Matorel and Luis Albán helped on the field experiments in Peru. Rosa Manrique, José Reyes and Hernán Vásquez assisted on the field experiments in Chile. Frits (G. M. J.) Mohren and Percy Jiménez facilitated the co-ordination of tasks. This work was supported by the EU-INCO project ICA4-CT-2001-10051 (www.biouls.cl/ enso/). M. H. thanks also the dutch NWO Meervoud Program.

\section{References}

Aceituno P, Montecinos A (1992) Análisis de la estabilidad de la relación entre la Oscilación del Sur y la precipitación en América del Sur. In: Paleo ENSO Records. International Symposium (eds Ortlieb L, Macharé J), pp. 7-13. ORSTOM/CONCYCET, Lima.

Allan R, Lindesay J, Parker D (1996) El Niño Southern Oscillation and Climatic Variability. CSIRO, Australia.

Arce P, Balboa O (1989) Seasonality in rooting of Prosopis chilensis cuttings and in-vitro micropropagation. Forest Ecology and Management, 40, 163-173.

Austin MP, Williams OB (1988) Influence of climate and community composition on the population demography of pasture species in semi-arid Australia. Vegetatio, 77, 43-49.
Bernex de Falen N, Reves B (1988) Atlas Regional de Piura. Centro de Investigación y Promoción del Campesinado (CIPCA), Piura y Pontificia Universidad Católica del Peru, Lima, Peru.

Bowers JE (1997) Demographic patterns of Ferocactus cylindraceus in relation to substrate age and grazing history. Plant Ecology, 133, 37-48.

Brown JH, Valone TJ, Curtin CG (1997) Reorganization of an arid ecosystem in response to recent climate change. Proceedings of the National Academy of Sciences of the United States of America, 94, 9729-9733.

Cobb KM, Charles CD, Cheng H et al. (2003) El Niño/Southern Oscillation and tropical Pacific climate during the last millennium. Nature, 424, 271-276.

Collins M (2000) Understanding uncertainties in the response of ENSO to greenhouse warming. Geophysical Research Letters, 27, 3509-3512.

Cook ER (1985) A time series analysis approach to tree ring standardization. PhD Dissertation, University of Arizona, Tucson, $171 \mathrm{pp}$.

Fredrickson EL, Estell RE, Laliberte A et al. (2006) Mesquite recruitment in the Chihuahuan Desert: historic and prehistoric patterns with long-term impacts. Journal of Arid Environments, 65, 285-295.

Fritts HC (1976) Tree Rings and Climate. Academic Press, London.

Fuentes ER, Jaksic FM, Simonetti JA (1983) European rabbits versus native rodents in central Chile: effects on shrub seedlings. Oecologia, 58, 411-414.

Fuentes ER, Otaiza RD, Alliende MC et al. (1984) Shrub clumps in the Chilean matorral vegetation: structure and possible maintenance mechanisms. Oecologia, 42, 405-411.

Grissino-Mayer HD (2001) Evaluating cross-dating accuracy: a manual and tutorial for the computer program COFECHA. Tree-Ring Research, 57, 205-221.

Gutiérrez JR, Holmgren M, Manrique R et al. (2007) Reduced herbivore pressure under rainy ENSO conditions could facilitate dryland reforestation. Journal of Arid Environments (in press).

Gutiérrez JR, Meserve PL, Herrera S et al. (1997) Effects of small mammals and vertebrate predators on vegetation in the Chilean semiarid zone. Oecologia, 109, 398-406.

Holmgren M, Scheffer M (2001) El Niño as a window of opportunity for the restoration of degraded arid ecosystems. Ecosystems, 4, 151-159.

Holmgren M, Scheffer M, Ezcurra E et al. (2001) El Niño effects on the dynamics of terrestrial ecosystems. Trends in Ecology and Evolution, 16, 89-94.

Holmgren M, Stapp P, Dickman CR et al. (2006) Extreme climatic events shape arid and semiarid ecosystems. Frontiers in Ecology and the Environment, 4, 87-95.

Intergovernmental Panel on Climate Change. (2001) Climate Change 2001: Synthesis Report. Third Assessment Report of the Intergovernmental Panel on Climate Change (eds Watson RT and the Core Writing Team), Cambridge University Press, Cambridge.

Jaksic FM, Fuentes ER (1991) Ecology of a successful invader: the European rabbit in central Chile. In: Biogeography of Mediterranean Invasions (eds Groves RH, di Castri F), pp. 273-283. Cambridge University Press, Cambridge. 
López BC, Rodríguez R, Gracia CA et al. (2006) Climatic signals in growth and its relation to ENSO events of two Prosopis species following a latitudinal gradient in South America. Global Change Biology, 12, 897-906.

López BC, Sabaté S, Gracia CA et al. (2005) Wood anatomy, description of annual rings, and responses to ENSO events of Prosopis pallida H.B.K., a wide-spread woody plant of arid and semi-arid lands of Latin America. Journal of Arid Environments, 61, 541-554.

López-Cortes F, López D (2004) Antecedentes bioclimáticos del Parque Nacional Bosque Fray Jorge. In: Historia Natural del Parque Nacional Bosque Fray Jorge (eds Squeo FA, Gutiérrez JR, Hernández IR), pp. 45-60. Ediciones Universidad de La Serena, Chile.

Lynch J (1995) Root architecture and plant productivity. Plant Physiology, 109, 7-13.

McPhaden MJ (2004) Evolution of the 2002/03 El Niño. Bulletin of the American Metereological Society, 85, 677-695.

Millennium Ecosystem Assessment (2005) Ecosystems and Human Well-Being: Desertification Synthesis. World Resources Institute, Washington, DC.

Noy-Meir I (1973) Desert ecosystems: environment and producers. Annual Review of Ecology and Systematics, 4, $25-45$.

Ortlieb L (2000) The documented historical record of El Niño events in Peru: an update of the Quinn record (sixteenth through nineteenth centuries). In: El Niño and the Southern Oscillation: Multiscale Variability and Global and Regional Impacts (eds Díaz HF, Markgraf V), pp. 207-295. Cambridge University Press, Cambridge.

Pasiecznik NM, Felker P, Harris PJC et al. (2001) The Prosopis Juliflora - Prosopis Pallida Complex: A Monograph. HDRA, Coventry, UK.

Sankaran M, Hanan NP, Scholes RJ (2005) Determinants of woody cover in African savannas. Nature, 438, 846-849.

Sankaran M, Ratnam J, Hanan NP (2004) Tree-grass coexistence in savannas revisited - insights from an examination of assumptions and mechanisms invoked in existing models. Ecology Letters, 7, 480-490.
Scholes RJ, Archer SR (1997) Tree-grass interactions in savannas. Annual Review of Ecology and Systematics, 28, 517-544.

Soto G, Ulloa F (1997) Diagnóstico de la desertificación en Chile. CONAF/FAO/PNUMA, La Serena, Chile.

Squeo FA, Arancio G, Gutiérrez JR (2001) Libro Rojo de la Flora Nativa de la Región de Coquimbo y de los Sitios Prioritarios para su Conservación. Ediciones de la Universidad de La Serena, La Serena, Chile.

Squeo FA, Aravena R, Aguirre E et al. (2006) Groundwater dynamics in a coastal aquifer in north-central Chile: implications for groundwater recharge in an arid ecosystem. Journal of Arid Environments, 67, 240-254.

Squeo FA, Holmgren M, Jiménez M et al. (2007) Tree establishment along an ENSO experimental gradient in the Atacama desert. Journal of Vegetation Science (in press).

Squeo FA, Olivares N, Olivares S et al. (1999) Grupos funcionales en arbustos desérticos definidos en base a las fuentes de agua utilizadas. Gayana Botánica, 56, 1-15.

Strauss SY, Agrawal AA (1999) The ecology and evolution of plant tolerance to herbivory. Trends in Ecology and Evolution, 14, 179-185.

Timmermann A, Oberhuber J, Bacher A et al. (1999) Increased El Niño frequency in a climate model forced by future greenhouse warming. Nature, 398, 694-697.

Toft CA (1995) A 10-year demographic study of rabbitbrush (Chrysothamnus nauseosus): growth, survival and water limitation. Oecologia, 101, 1-12.

Trenberth KE, Hoar TJ (1997) El Niño and climate change. Geophysical Research Letters, 24, 3057-3060.

Tudhope AW, Chilcott CP, McCulloch MT (2001) Variability in the El Niño-Southern Oscillation through a glacial-interglacial cycle. Science, 291, 1511-1517.

Vilela J (2002) Reforestación participativa en Piura durante el Fenómeno El Niño 1996-1997: La experiencia en las C.C. de Sechura, Catacaos y Castilla. Serie Lecciones Aprendidas No 8, INRENA - Proyecto Algarrobo, Peru, 34 pp.

Watson IW, Westoby M, Holm AMcR (1997) Demography of two shrub species from an arid grazed ecosystem in western Australia 1983-93. Journal of Ecology, 85, 815-832. 